\title{
PENSAR O DISCURSO DE QUEM NÃO PODE FALAR EM SITUAÇÃO DE IGUALDADE
}

Fernando Caetano ${ }^{1}$

RESUMO: A ideia de Sujeito de Direito é um imperativo da Filosofia do Direito que universaliza os Direitos Humanos. Acontece que o pretenso universalismo não dá conta da realidade. A criação discursiva, histórica e filosófica do sujeito acaba por instaurar um outro sujeito que náo frui efetivamente dos direitos do Sujeito de Direito. Esse outro sujeito é incapaz de constituir direitos para si, porque não pode falar em igualdade social. Pensar o discurso de quem não pode falar em igualdade é repensar a própria forma como se produzem e reproduzem as estruturas de dominaçáo que marginalizam e subalternizam sujeitos.

PALAVRAS-CHAVE: Sujeito de Direito. Marginalidade. Subalternidade.

\section{THINKING THE SPEECH OF THOSE WHO CANNOT SPEAK IN SITUATION OF EQUALITY}

ABSTRACT: The idea of Subject of Law is an imperative of the Philosophy of Law that universalizes Human Rights. It turns out that the alleged universality finds no support in reality. The subject's discursive, historical and philosophical creation ends up creating an "Other Subject" that does not effectively enjoy the rights of the Subject of Law. This "Other Subject" is unable to constitute rights for himself because he cannot speak on equal terms. To think about the discourse of those who cannot speak equally is to rethink the way in which the structures of domination that marginalize and subordinate subjects are produced and reproduced.

KEYWORDS: Subject of Law. Marginality. Subalternity.

\footnotetext{
1 Universidade Federal de Minas Gerais (UFMG), Belo Horizonte - MG - Brasil. Doutorando em Direito. Pontifícia Universidade Católica (PUC-Minas), Belo Horizonte - MG - Brasil. Professor de Teoria da Constituição e Direito Constitucional. Pesquisa realizada com o apoio da Fundação de Amparo à Pesquisa do Estado de Minas Gerais (FAPEMIG) e do Programa de excelência acadêmica (PROEX/CAPES). Orcid: https://orcid.org/0000-00029541-3953. fernando.caetanorjr@gmail.com.
} 


\section{Da universalidade à realidade}

A categoria universal denominada sujeito de direito, que surge nos postulados da filosofia do sujeito, incitou a crítica decolonial que contrapóe a ideia de sujeito de direito com a de marginalidade. Essa crítica busca verificar a ficção jurídica em que consiste o sujeito de direito, quando observado em contraste à realidade dos sujeitos subalternos (marginais).

O sujeito de direito como categoria universal parece não ser capaz de garantir a eficácia dos direitos inerentes a todos os sujeitos, principalmente quando os destinatários desses direitos pertencem a certos grupos sociais, compostos por sujeitos subalternos, que não podem falar em situação de igualdade na sociedade.

O objetivo deste artigo é demonstrar que a categoria do sujeito de direito refere-se apenas a um grupo que está no centro de uma estrutura social e que os direitos inerentes a esses sujeitos perdem a eficácia de sua fruição quanto mais o sujeito (ou o grupo de sujeitos) desloca-se do centro à margem da sociedade. Essa situação evidencia, assim, a relação de subalternidade existente entre o sujeito marginal e o sujeito de direito.

O referencial teórico adotado parte do conceito de sujeito de direito e de sua relação com o capitalismo, conforme postulado pela filosofia do sujeito, e desemboca na crítica elaborada pelo pensamento decolonial sobre a pretensa universalidade do sujeito.

Nesse sentido, a ideia de sujeito de direito será contestada pela crítica decolonial. Isso se dará, principalmente, por meio da ideia de marginalidade, extraída da obra do sociólogo peruano Anibal Quijano, e da ideia de subalternidade, extraída da obra da professora indiana Gayatri Chakravorty Spivak.

Por meio dessa contraposição de conceitos, pretende-se traçar linhas e concepçôes iniciais sobre o debate que aqui se propóe: o sujeito subalterno tem condiçôes de constituir direitos?

\section{A ideia de sujeito de direito}

A construção da concepção histórica e filosófica de sujeito, de onde deriva a ideia de sujeito de direito, é objeto de ampla produção literária. Aqui se propóe uma breve reconstrução do movimento do pensamento nesse sentido.

Náo é objeto central deste trabalho remontar pormenorizadamente quem é o sujeito de direito. Nós já sabemos quem ele é. É aquele da teoria hegemônica, masculina, branca, europeia ou norte-americana, pertencente aos altos extra- 
tos sociais, às classes dominantes, que construiu para si uma categoria formal abstrata que atende aos interesses desses mesmos grupos sociais dominantes. É o burguês que não é nobre, mas que requer para si direitos pelo fato de ser humano, isto é, por meio de um processo de consciência e de tomada do poder econômico, utiliza-se do direito para se garantir.

O objetivo, aqui, é o de demonstrar, brevemente, aspectos relevantes da produção bibliográfica de onde se deriva a categoria sujeito de direito, bem como a distância entre essa ideia e a realidade de sujeitos subalternos/marginais.

Em sua Arqueologia do Sujeito, o filósofo francês Alain de Libera (2013), propóe uma leitura arqueológica pós-foucaultiana da tese de Heidegger sobre a invenção da subjetividade como ponto de passagem decisivo da história da subjetividade moderna, não como acontecimento, mas como figura discursiva que emerge e se desenvolve paralelamente na teoria moderna (LIBERA, 2013).

Ao discutir quando se deu o surgimento do sujeito, Libera destaca que o sujeito "não é uma criação moderna, nem tampouco um conceito psicológico, menos ainda uma invenção de Descartes” (LIBERA, 2013, p. 195). O Autor aponta que, em Kant, ocorreram os inícios mais generalizadamente alegados do sujeito pensante dito moderno, sem prejuízo de apontar traços do que se busca em produçóes anteriores.

Libera ressalta que o sujeito pensante dos modernos não é - nem deve ser - tomado como a sombra projetada do sujeito pensante dos escritos teológicos ou da própria teologia sobre aquilo que se chama "a questáo do sujeito".

Entretanto, o autor conclui que o sujeito pensante, isto é, o homem enquanto sujeito e agente do pensamento, é um produto de um encontro histórico entre a teologia e a filosofia, que durou da Antiguidade tardia à Idade Clássica. Aponta, ainda, como o problema fundamental de onde emergiu a noção moderna do sujeito, a relação do sujeito com a pessoa e, após, a escolástica protestante que inspirou Leibniz, que colocava a questão inversa: "o que faz de uma pessoa um sujeito?”.

Por fim, afirma que, paradoxalmente, o pensamento clássico e a neoescolástica sustentaram, em graus diversos, que "personalidade é o que constitui o sujeito inteligente como sujeito primeiro de atribuição de tudo que lhe convém" (LIBERA, 2013, p. 216), centro de pertencimento de tudo que lhe é atribuído; que ele é o constitutivo de um eu, possuindo sua natureza, sua existência seus atos de consciência e de liberdade.

Eleanor Macdonald (1991), ao discutir o problema com sujeitos, propóe a radicalização e a superação das estruturas de definição do sujeito, a partir da recusa dos fundamentos tradicionais, em um primeiro momento, colocan- 
do como problemática central a questão da conceituação do sujeito, tanto no pós-estruturalismo, quanto em teorias marxistas e feministas. A necessidade de resolver questóes teóricas sobre o sujeito se dá, para Macdonald, como forma de possibilitar mudanças sociais. Ela divide a problematização e a desconstrução da noção de sujeito no pós-estruturalismo em dois grupos, os que desconstroem a noção de sujeito com base na linguagem (Lacan, Derrida, Kristeva) e Foucault, que, menos preocupado com a estrutura da linguagem, desconstrói a noção de sujeito a partir das suas noçôes de discurso e de compreensão do poder (MACDONALD, 1991).

A crítica se dá em face da concepção cartesiana de sujeito, que é a do sujeito capaz de raciocinar a própria existência, sujeito autônomo e individual; um ator que toma decisóes, uma visão de sujeito que serve a modelos liberais de política. Mas fora da problemática liberal, a noção de sujeito é questionada principalmente quando confrontada com a noção de consciência de classe e do papel do sujeito nas mudanças sociais, sendo a crença no sujeito cartesiano benéfica à manutenção do capitalismo (MACDONALD, 1991).

A autora conclui afirmando que o sucesso de uma re-teorização do sujeito requer uma análise multidimensional que combine distintas abordagens, de modo que nenhuma possua um status determinante. Afirma, ainda, que existem questôes críticas a serem perguntadas, como: "em que meios a variedade de relacionamentos sociais frustra ou contribui com as estruturas de dominação?” e "como a racionalidade dominante reflete em práticas institucionais?". Sustenta que essas questốes demandam uma contextualização histórica e a consideração da racionalidade, da relacionalidade e, ainda, de serem informadas pelos tipos de valores emancipatórios esquecidos pelos discursos pós-estruturalistas e, idealmente, que elas devem ser sensíveis à diferenças, à marginalidade e aos discursos das teorias feministas e antirracistas, com a esperança de que caminhos sejam encontrados para entender o problema com os sujeitos através dessas dimensóes e da relação entre elas (MACDONALD,1991, p. 66).

Alain Touraine, ao trazer a conceituação de indivíduo, aponta esse aparece como sendo náo mais que a unidade particular em que se mesclam a vida e o pensamento, controlando sua vivência e se transformando em ator que participa das e transforma as relaçóes sociais (TOURAINE, 1994a).

Em The Subject is Coming Back ["O retorno do sujeito"], Touraine reapresenta sua análise da Modernidade e também reafirma, sem reservas, sua ideia de que todos compartilhamos do direito de combinar, de uma forma peculiar, nossa participação no mundo, inclusive defendendo ou criando uma proposta cultural. "Combinar de forma peculiar" em Touraine se refere a ideia de que "nós 
podemos viver juntos sendo iguais ou diferentes se reconhecermos mutuamente nossos direitos de participar na economia global e, ao mesmo tempo, nosso direito de ser diferente dos demais" (TOURAINE, 2005, p. 202).

Ao adentrar na questão do individualismo, Touraine aponta que a sociedade moderna define o indivíduo pelo lugar que ele ocupa em um conjunto - o individualismo, portanto, não tem conteúdo próprio. Touraine identifica, no pensamento liberal, a associação entre individualismo e tolerância, e a recusa da exclusão de uma categoria social ou nacional. Para Touraine, o custo social de mecanismos econômicos e políticos de desenvolvimento é muito elevado: "eles destroem para criar, provocam mobilizaçóes econômicas ou guerreiras que dividem, opóem, conquistam antes de integrar e convencer" (TOURAINE, 1994a, p. 256). Touraine conclui dizendo que o sujeito afirma-se contra a dominaçáo dos aparelhos políticos e sociais e sua liberdade está ligada ao fato de pertencer a uma cultura. A modernização, assim, exige a ruptura, mas também a continuidade.

Touraine afirma que o sujeito não é um absoluto e seu conteúdo não é o mesmo da razão, não estando, por isso, reduzido a particularismos sociais, culturais e individuais. $\mathrm{O}$ sujeito não se constitui. $\mathrm{O}$ Eu só afirma-se pela ligaçáo entre a afirmação de si e a luta defensiva contra os aparelhos de produção e de gestão. Sustenta, ainda, que devemos desconfiar de todos os modelos de perfeição, pois o totalitarismo fez desaparecer a ideia de construção de uma sociedade do futuro (mais justa e mais avançada, mais moderna e mais livre) e o objetivo do presente não são "amanhás radiosos", mas sonhar em viver de outro modo uma "cultura alternativa" que não vai vir da homogeneidade nem do sectarismo (TOURAINE, 1994b, p. 317).

István Mészáros afirma, ao analisar a crítica Marxista sobre a alienação do sujeito, que o "verdadeiro homem" - a verdadeira "pessoa humana" - não existe realmente na sociedade capitalista, salvo em forma alienada e reificada, como sob forma de "trabalho" e "capital" (propriedade privada). Em consequência, a afirmação do "homem" deve proceder mediante a negação das relaçôes sociais de produção alienada. (MÉSZÁROS, 2006, p. 106).

As relaçóes sociais entre o meio, os detentores dos meios de produção e os detentores da força de trabalho, dão-se em um espectro amplo e múltiplo de inter-relaçóes que constituem uma estrutura social criada de forma a se reproduzir, em que a força de trabalho e todas as outras coisas são reduzidas a um número, a um valor: o capital.

Nesse processo, o trabalho se torna um meio, não um existir do sujeito, que labora em funçáo do seu existir. $\mathrm{O}$ existir ocorre apenas nos momentos em 
que sua força de trabalho já foi coisificada e se procedeu a mediação social por meio do capital.

O sujeito leva o capital de novo ao mundo, como única forma de acessar os produtos (que produziu, mas não são seus), na medida em que foi valorada e mediada sua força de trabalho, coisificada por meio da entrega do produto ao dono do meio de produção e da consequente, esperada e necessária, mediação reificada do trabalho assalariado - e essa seria a alienação do sujeito em Marx.

A superação dessa condição só pode se dar, segundo Mészáros (ao interpretar os Manuscritos econômico-filosóficos, de Marx (2004 [1844]), por meio de um domínio teórico dos complexos problemas econômico-sociais nele envolvidos. A posição política capitalista não se coaduna com esse entendimento, nem sequer com a superação da estrutura. Essa é a razão da oposição de Marx ao modelo capitalista. Toda a sua crítica é uma "antecipação" da evolução social e econômica (MÉSZÁROS, 2006).

Sobre o papel da consciência de classes nessa relação, são valiosas as liçóes de György Lukács em sua interpretação do materialismo histórico de Marx, ao dizer que a classe burguesa tem a consciência da dominação sobre a classe operária e, já em posição defensiva, luta para subsistir, de forma individualista e egoística. A consciência de classe do dominador é papel fundamental na dominação, pois, como já dito, cria as estruturas organizadas capazes de influenciar decisivamente o papel da classe na sociedade (LUKÁCS, 2003).

Louis Althusser acrescentaria que o papel da aparelhagem estatal é, então, o de garantir, pela lei ou pela força (politicamente), as condiçóes de reprodução do modelo de produção, que são, em última análise, relações de exploração. Isso porque o Estado, como o é, foi colocado em posição dominante por uma aparelhagem capitalista (ALTHUSSER, 1976).

O sujeito de direito corresponde à classe que consubstancia a ideologia burguesa de sujeito que, independentemente da condição de honra da nobreza, requer o reconhecimento de direitos que lhe são inerentes em razão da condição de humano.

Assim, o sujeito de direito é uma categoria de reconhecimento jurídico e político tida como naturalmente evidente. O substrato econômico não foi suficiente para garantir os direitos dos sujeitos burgueses, sendo necessário conquistar o reconhecimento político-jurídico de sua condição enquanto classe sujeita a direitos.

Celso Naoto Kashiura Júnior, em sua tese de doutorado analisa esse fato histórico: 
Nenhuma sociedade historicamente anterior à sociedade burguesa pôde conhecer a forma sujeito de direito em sua dimensão universal. Nenhum modo de produçáo historicamente anterior ao capitalista determinou que os homens fossem todos igualmente alçados à qualidade de proprietários em potencial, núcleos da vontade livre, portadores abstratos de direitos. Nenhuma forma histórica de sociedade a não ser aquela correspondente à produção capitalista pôde exaltar ideologicamente as determinaçóes formais do sujeito de direito, a igualdade e a liberdades jurídicas, o voluntarismo e a "personalidade", correspondentes à circulação mercantil universalizada - enquanto, na produção os homens enfrentam a sua própria reduçáo à forma de mercadorias, exploração, dominação de classe (KASHIURA JR, 2012, p. 165).

A partir dessa análise podemos concluir que o sujeito se constitui como subjetividade jurídica ou proprietária a partir da reprodução das relaçóes de produção capitalistas. A categoria de sujeito de direito tem fundamento histórico no direito de propriedade.

A crise da categoria universal de sujeito de direito já é observada como representativa da ideologia burguesa formalmente criada para reproduzir o sistema de produçáo capitalista. O sujeito de direito é aquele que nasce da consciência de classe e da ideologia do burguês: este é quem ele é; mas o que é o sujeito de direito?

A origem demonstrada não exaure a questão, pois não define o que é especificamente essa categoria que daí surgiu. Cabe adentrar nessa questão: a ideologia do sujeito de direito é uma percepção ocidental que reflete a ideia de que todos, em razão unicamente de sua condição humana, são detentores de direitos naturais universalizados na lei.

O problema é exatamente que a categoria sujeito de direito não dá conta da realidade social. Acaba, portanto, por constituir uma categoria formal, de perspectiva universalista, que é alheia ao sujeito real na sociedade. Não é uma questão dos direitos formalmente postos, mas sim uma questão da contradição entre a pretensão de universalização e a (in)efetiva fruição destes direitos por sujeitos reais.

Visto o que é o sujeito de direito percebemos claramente que a sociedade humana não é composta de sujeitos de direito, mas sim de um grupo pequeno de sujeitos que fruem efetivamente de seus direitos, de um lado; e de grupos que compóem a maioria da sociedade humana e que não fruem efetivamente dos tais direitos do sujeito universal de direitos, de outro. 
O mesmo pode ser explicado da seguinte forma: sujeito de direito não é uma categoria universal como pretende formalmente ser, mas sim, a universalização de uma condição material de um grupo - dominante - que acaba por produzir e reproduzir a injustiça.

O próximo passo é verificar: qual a ideia por trás do fato de que alguns indivíduos e grupos sociais se encontram em relação de subalternidade em relação a outros grupos sociais de uma mesma sociedade? Ou seja: o que faz com que alguns sujeitos não sejam sujeitos de direito?

\section{A ideia de marginalidade}

Anteriormente, delineou-se a categoria universal do sujeito de direito e apresentou-se a crítica segundo a qual essa categoria homogênea corresponde apenas a uma concepção formal da igualdade, sem vínculo com a realidade, em que somente um grupo de sujeitos, situados no centro da estrutura social, pode constituir direitos para si e fruir dos direitos que deveriam ser efetivamente fruídos por todos em razão da condição humana.

O passo seguinte, então, é investigar os sujeitos que se encontram afastados do centro da estrutura social, à margem, sujeitos que não constituem direitos para si, nem fruem efetivamente dos direitos que lhe seriam inerentes caso estivessem em situação de igualdade em relação ao sujeito de direito. Ou seja, busca-se investigar qual a ideia por trás da estratificação da sociedade.

A questão da margem, da marginalidade, da marginalização e dos marginais permeia os debates econômico, político, jurídico e social. Muitas vezes, os termos adquirem acepçóes diversas, às vezes pejorativas e sempre politicamente inclinadas. Como já mencionado na introdução deste trabalho, a ideia de marginalidade será tratada a partir da análise das "Notas sobre o conceito de marginalidade”, do sociólogo peruano Aníbal Quijano.

Quijano aponta, na utilização literária contemporânea, duas significações para marginalidade: a chamada "teoria da personalidade marginal", desenvolvida na sociologia norte-americana, e a "teoria da situação social marginal”, que surge nas produçóes literárias relacionadas ao subdesenvolvimento, muito especialmente na América Latina (QUIJANO, 1978, p. 14).

A primeira delas, a teoria da personalidade marginal, surgiu de uma ideia de desorientação psicológica presente nos indivíduos submetidos a uma situação de conflito entre duas culturas antagônicas e em relação de dominação.

$\mathrm{O}$ indivíduo marginal faria parte da cultura dominada e sofreria atraçóes e repulsas entre os dois mundos. A marginalidade, nesse contexto, é um fenôme- 
no psicológico individual, uma marca da personalidade. Logo após apresentar essa perspectiva, Quijano propóe uma crítica a ela: o autor observa que faltam elementos teóricos que permitam precisar a natureza e as características sociais de tal personalidade marginal. Assim, essa ideia não passaria de um estereótipo, que resulta em uma caricatura, uma imagem distorcida da realidade.

De fato, o caráter fundamentalmente psicológico do conceito de "marginalidade" incorporado a essa teoria dificulta sua utilizaçáo como instrumento de análise psicológica. A ênfase nas características psicológicas do indivíduo marginal tende a fazer que se perca de vista o que constitui a condição mesma de marginalidade, isto é, o fato de se pertencer ao mesmo tempo a vários mundos culturais, sem se estar incorporado plenamente a nenhum deles em particular, ou seja, o fato de se habitar uma zona cultural situada tanto dentro como fora das culturas em conflito (QUIJANO, 1978, p. 15-16).

Do exposto, extrai-se que, para Quijano, a teoria da personalidade marginal é válida ao constatar que a marginalidade nasce do conflito cultural, isto é, da ausência de incorporação plena do sujeito na zona cultural onde está situado.

Quijano rejeita a ideia de que as características psicológicas são uma condição da marginalidade. Como forma de aproximar marginalização à realidade, o autor aponta a necessidade de uma vinculaçáo do conceito ao problema das relaçóes entre os grupos sociais. Com isso, busca mostrar que a marginalidade é proposta como uma inconsistência entre o grupo social de pertencimento e o grupo de referência e explica que marginal seria aquele que usa como grupo de referência um grupo ao qual não pertence e experimenta barreiras que impediriam sua integração ao grupo de referência (QUIJANO, 1978).

A marginalidade, então, deve ser concebida, nesse sentido, como uma condição em que o sujeito - marginal - pertence a um grupo cultural dominado, mas tem a referência de seu dever ser em um grupo do qual não pertence e não consegue pertencer: o grupo cultural dominante.

Ainda dentro da análise da teoria da personalidade marginal, Quijano apenas aceita o aspecto psicológico como efeito da marginalidade, nunca como sua condição mesma. A marginalidade também é definida na referida teoria a partir de um complexo de papéis-status institucionalizados. É justamente na inconsistência da realidade do indivíduo com as expectativas dos papéis-status socialmente observáveis que surge o fenômeno da marginalidade (QUIJANO, 1978). 
Importante, também, mencionar a derivação de tal teoria: a corrente teórica fundada em sua aplicação na explicação de mecanismos de mudança cultural, que, para Quijano, são verdadeiros processos de introdução e difusão de inovaçóes, como cumpre destacar:

As personalidades marginais são percebidas como personalidades inovadoras por excelência (...) o indivíduo marginal está normalmente empurrado ou estimulado por sua situação a tratar de introduzir mudanças em sua sociedade. (...) Os indivíduos marginais são desse modo, agentes da mudança social e cultural, e isso constitui uma das vias mais adequadas do cancelamento da marginalidade. (QUIJANO, 1978, p. 17).

A teoria da personalidade marginal é uma perspectiva da marginalidade no indivíduo, da qual se podem depreender três aspectos importantes: (1) a marginalidade surge do conflito gerado pela referência que o sujeito projeta em um grupo culturalmente dominante, quando pertence a um grupo culturalmente dominado; (2) os grupos sociais estabelecem papéis-status: a marginalidade ocorre quando há distância entre a expectativa social sobre o indivíduo e a realidade do sujeito no que se refere a esses papéis sociais; e (3) os grupos marginais, em razão de sua condição, tendem a buscar a inovação das concepçôes sociais, com o evidente objetivo de plena integração à zona cultural em que se situam.

Esse último aspecto é importante para este trabalho, pois situa os marginais como agentes da mudança social e cultural e apresenta um mecanismo de cancelamento da marginalidade por meio da ação ativa do marginal na construçáo social. Pensar a capacidade inovadora desses sujeitos que, a princípio, náo podem constituir direitos, nem fruir efetivamente dos direitos do sujeito de direito, é pensar o discurso de quem náo pode falar em igualdade.

A segunda teoria da marginalidade, que se desenvolve independentemente da teoria da personalidade marginal, caracteriza-se pelo deslocamento da ênfase no indivíduo para o foco nos grupos sociais: trata-se da teoria da situação social marginal.

O termo marginal, em sua concepção social, surgiu da posição física onde se aglomeravam, em condiçóes precárias, os grupos sociais formados após a Segunda Guerra Mundial pelos processos de migração e urbanização: à margem das cidades. Os problemas gerados por esse processo ficaram conhecidos como “problema das populaçóes marginais”. (QUIJANO, 1978, p. 18).

Os limites físicos da denominação deixaram de ser as únicas razóes para seu uso: a questão da moradia; a falta de acesso a serviços básicos de água, sane- 
amento básico, luz e transportes foram incorporadas à condição de substandard, culminando no fato de que quem não tinha acesso a esses direitos mínimos era denominado marginal, independentemente da localização física dos povoamentos (QUIJANO, 1978).

O termo substandard refere-se àquilo que é precário, abaixo do padrão. A condição de substandard das populações marginais denota a precariedade da experiência abaixo dos padrôes dos grupos sociais não marginais.

Quijano traz em suas "Notas sobre o conceito de marginalidade social” uma revisão literária a partir da qual destaca as sete variações mais utilizadas do termo marginalidade. Cumpre as observar: (1) a marginalidade como situação ecológica: a mais antiga concepção do termo, relacionada à posição dos grupos sociais imigrantes à margem das cidades, que depois se expande para o caráter abaixo do padrão desses grupos; (2) a marginalidade como cidadania limitada: é um estado de não fruição efetiva dos direitos inerentes ao sujeito de direito, que torna o sujeito menos capaz de participar do processo de desenvolvimento econômico; (3) a marginalidade como participação na cultura da pobreza: concebe a marginalidade como um conjunto de indivíduos pobres e incapazes de perceber seus problemas individuais como problemas coletivos de classe. $\mathrm{O}$ marginal, então, é um desclassificado, equivale à carência de identidade sociocultural; (4) a marginalidade como atraso no desenvolvimento econômico: concepção de que marginais são os grupos sociais que não podem usufruir dos benefícios materiais e culturais do desenvolvimento econômico. $\mathrm{O}$ conceito se refere aos grupos rurais em relação a grupos urbanos da mesma sociedade; (5) a marginalidade como falta de participação no processo de integração da sociedade: consiste na ausência de participação tanto no processo decisório da sociedade quanto na fruição de bens e serviços, pela inexistência de relaçóes de grupo e/ou existência de barreiras sociais. (6) a marginalidade como situação inconsistentemente estruturada na sociedade: assume um caráter extremamente complexo, que se refere à inconsistência para o grupo do processo de estruturação, de manifestação dos elementos culturais e de posição do próprio grupo na sociedade. O grupo não se identifica na posição social marginal em que se encontra; (7) a marginalidade como não-pertencimento ao sistema dominante numa sociedade: refere-se aos grupos que não fazem parte do sistema dominante. Os marginais, então, têm designados papéis subalternos na divisão do trabalho e participam de forma inferior no universo social e na cultura dominante da sociedade (QUIJANO, 1978).

É possível observar como essa relação de marginalidade estratifica a sociedade em diversas camadas e níveis que partem da dominação dos donos dos 
meios de produção sobre os detentores da força de trabalho, o proletariado dominado.

As relações de poder que daí derivam são hoje demasiadamente plurais, não se podendo identificar mais as razóes da dominação de uns grupos sociais sobre outros na forma de classes antagônicas apenas no substrato econômico.

A igualdade econômica, em uma situação hipotética de abundância de capital e distribuição equitativa dos recursos, não faria sumir os grupos sociais dominantes e dominados. Isso porque a dominação se dá, também, em virtude de um substrato que é jurídico-político, derivado da estratificação social em classes cujos substratos econômicos se confundem. Os grupos dominantes e dominados são compostos por indivíduos em diversas realidades econômicas e são unidos por bases outras de ordem moral, jurídica, política, religiosa etc.

Portanto, é acertada a visão de que as diversas interpretações de marginalidade não se excluem, mas, sim, referem-se a substratos diversos e interseccionais, que fundamentam a separação de uma dada sociedade em grupos em relaçáo de dominação.

A dominação se dá em razão da posição geográfica que o sujeito ocupa na sociedade, seja em relação a campo/cidade ou centro/periferia; da reduzida apropriação das inovaçóes tecnológicas e culturais ou, ainda, em razão da impossibilidade do pleno exercício da cidadania por meio da experiência humana em desigualdade de condiçôes de fruição do tempo e da vida; ou seja: a dominação se dá pela ausência de integração ou de pertencimento do grupo social à estrutura social como ela é concebida nos moldes do grupo opressor; ou por várias dessas razóes simultâneas, ou ainda por outras, capazes de dividir um grupo social em grupos sociais antagônicos.

O que é central na questão da marginalidade é: a sociedade em que a marginalidade se produz é aquela em que os grupos existentes, diversos e plurais, apresentam problemas de integração, estabelecendo relaçóes de dominação econômica e/ou jurídico-política.

A marginalidade pode se apresentar como marginalidade total, ou seja, como o pertencimento e participação dos membros apenas nos elementos e/ou estruturas marginais em cada um destes setores institucionais; ou como marginalidade correspondente a um ou mais desses setores institucionais. Nestes termos, poder-se-á identificar marginalidade social total ou, então, a marginalidade econômica, ou a marginalidade social, ou a marginalidade política, ou a marginalidade ecológica, ou a marginalidade cultural e psicológico-social. (QUIJANO, 1978, p. 38). 
A dominação social, afirma Quijano, é espontaneamente gerada a partir da organização do grupo social e de seus elementos e o substrato econômico é, por excelência, uma forma de estratificação social geradora de marginalidade e dominação, mas não é o fundamento único dessa dominação. Os grupos sociais podem ser dominados inclusive em situação de homogeneidade econômica. Vejamos:

Toda sociedade complexa historicamente conhecida se organiza e se integra numa estrutura hierárquica de seus elementos. Do ponto de vista dos membros, isso se expressa e opera como um sistema de dominação social (...) Embora seja certo que a situação de marginalidade pode coincidir com a situação de dominado, isso não tem que assim ocorrer necessariamente, pois depende sempre da marginalidade concreta na qual esteja inserido um conjunto de membros da sociedade (...) Um conjunto de membros, pode ter, porém, uma situação de dependência ou dominada na estrutura básica da sociedade, e, não obstante pertencer a ela plenamente, e a marginalidade estar, em consequência ausente de sua existência na sociedade. Este é, sem dúvida, o caso das populaçóes trabalhadoras industriais numa sociedade industrial burguesa. (QUIJANO, 1978, p. 36).

Quijano está se referindo àqueles que "estão integrados na estrutura básica dos setores econômico-sociais e que se encontram, apesar disso, incorporados marginalmente ao setor político, ou cultural, ou ecológico, ou a todos esses ao mesmo tempo" (QUIJANO, 1978, p. 39).

Quijano define a marginalidade social como:

Um modo limitado e inconsistente de pertencimento e de participação na estrutura geral da sociedade, seja a respeito de certas áreas dentro de suas estruturas dominantes ou básicas, seja a respeito do conjunto destas, em todos ou em parte de seus setores institucionais. (QUIJANO, 1978, p. 39).

Infere-se, assim, que, na estrutura social, existem marginalidades que se distinguem de uma forma que não está encrustada no aspecto mais básico da sociedade, e que poderia ser resolvida com uma prática política inclusiva. Isso remete às formas de marginalização econômicas, que se solucionariam com uma distribuição mais igualitária do capital, da moradia, dos bens e dos serviços 
públicos. A ação que é necessária para combater esse tipo de marginalidade é realizada sobre o próprio grupo marginal.

Uma segunda forma de marginalidade, cujo debate já foi levantado anteriormente, é aquela segundo a qual os fundamentos da estratificação social em classes são encontrados na própria sociedade, não no grupo marginal. Essa perspectiva pressupóe um verdadeiro antagonismo conflituoso existencial entre o grupo marginal e o grupo dominante. As açóes no sentido de combater essa forma de marginalidade, então, são dirigidas à sociedade, e essa forma de marginalidade pode ser visualizada sempre que as classes são antagônicas: por estruturas sociais excludentes, por exemplo. Nesse sentido, é a própria estrutura básica da sociedade - da classe dominante, em específico - que precisa ser alterada para modificar a relação de subalternidade. Vejamos em Quijano.

Há marginalidade e marginalidade: uma que não afeta a sociedade em seu caráter básico, mas apenas em algum setor e nível dela, e que pode ser eliminada por uma ação sobre a marginalidade, mais que sobre a sociedade; outra, que pressupóe um conflito radical entre a existência marginal e a existência da estrutura básica da sociedade, porque esta existe enquanto aquela exista, e, em decorrência, esta forma de marginalidade não pode ser superada sem modificação da natureza da sociedade como tal. (QUIJANO,1978, p. 49).

Os substratos diversos das formas de marginalidade aqui apontados levam à reflexão de que as ferramentas para a alteração das relaçóes de dominação e marginalização também precisam ser múltiplas. E que uma mesma fórmula normalmente a fórmula do dinheiro - não serve para desmarginalizar todos os grupos dominados das sociedades plurais contemporâneas. Entretanto, poderíamos começar por aí: pela igualdade econômico-social, como forma de permitir a integração plena na sociedade e a capacidade real de buscar a igualdade jurídico-política, a possibilidade de falar, de constituir direitos.

Essa é a ideia de marginalidade, a ideia por trás da condição de sujeitos que não são "sujeitos de direito" e que servirá para a construção de uma categoria materialmente observável de um sujeito real, não um sujeito de direito, mas um sujeito de luta e resistência em busca dos direitos prometidos por essa categoria universal. Um sujeito que pertence à sociedade, mas não a integra completamente, em razão de dominações econômicas, culturais, sociais, políticas e jurídicas que o marginalizam. Vejamos como se construiu realmente esse outro sujeito na nossa história. 


\section{A realidade do sujeito subalterno}

A professora indiana Gayatri Chakravorty Spivak é uma das pessoas mais influentes dentro da crítica cultural contemporânea; Pode o subalterno falar? (SPIVAK, 2010) é considerado seu texto crítico mais polêmico, sendo amplamente difundido como uma referência essencial nos estudos do pós-colonialismo, com claras bases marxistas, pós-estruturalistas e desconstrucionistas.

A análise da obra tem por objetivo verificar, no trabalho de Spivak, a questão das marginalidades aplicadas ao contexto histórico da sociedade, o que acaba por produzir sujeitos subalternos contrapostos aos sujeitos de direito de que tratamos anteriormente.

Desvendar a questão trazida por Spivak, no sentido de identificar se o subalterno pode ou não falar na sociedade, é o meio pelo qual enfrento a questão que se coloca como o objeto central deste trabalho: saber se os grupos marginais, em uma dada sociedade, podem ou não constituir direitos para si.

O foco da análise de Spivak é a produção intelectual ocidental. Sua crítica se dirige exatamente à forma como são representados os sujeitos, questionando a própria condição de representação e a finalidade a que essa produçáo serve: aos interesses econômicos internacionais.

A conclusão de Spivak a respeito dessa temática nos parece muito interessante: a táo difundida crítica ao sujeito soberano realmente "inaugura um novo sujeito" (SPIVAK, 2010, p. 21, grifo nosso).

A proposição de Spivak traz a dualidade que constitui o objeto central deste trabalho. Seu argumento é o de que a produção teórica ocidental de homens brancos, ao representar o sujeito, dá-se de uma forma distorcida, que acaba por proporcionar as condiçóes para o surgimento de outro sujeito, distinto daquele das teorias universalistas: um sujeito da realidade subalterna.

Spivak quer identificar como as relaçóes coloniais produziram a forma como se entende e se dá voz aos sujeitos pertencentes aos grupos menos poderosos na sociedade, a quem denomina "subalternos". A autora critica principalmente a produção teórica sobre os sujeitos, realizada por homens, brancos, europeus, que falam sobre os subalternos de uma perspectiva externa à experiência real de suas vivências, em vez de reconhecerem e respeitarem o lugar de fala desses grupos. Para Spivak, essa postura colonial de produção intelectual distorce a realidade desses sujeitos, silencia os grupos subalternos e cria as condiçóes mesmas de sua subalternidade.

Na segunda parte de Pode o subalterno falar?, Spivak quer esclarecer a noção de violência epistêmica a partir da experiência da lei hindu, que, segundo a 
autora, foi até o século dezoito "internamente incoerente" e aberta nos dois extremos, legitimando uma estrutura polimorfa do funcionamento legal. Também utiliza o exemplo da educação indiana, que revela uma posição etnocentrista de hegemonização da educação indiana segundo um modelo colonialista perturbador, no qual a educação nativa se tornou a educação alternativa e a memória da cultura e da educação indiana tradicional precisaram de transcriçóes nos moldes coloniais para garantirem sua preservação (SPIVAK, 2010, p. 49).

Nesse contexto se exemplificam, na história indiana, formas de violências epistêmicas que operam uma tentativa de moldar - de forma heterogênea - uma sociedade em que os outros sujeitos náo podem falar e conhecer suas condiçôes. Nesse momento, Spivak questiona: "na divisão do trabalho do capital socializado, dentro e fora do círculo de violência epistêmica da lei e da educação imperialista, pode o subalterno falar?" (SPIVAK, 2010, p. 54, grifo nosso).

Para confrontar sua própria questão, a professora indiana passa a discorrer sobre o desenvolvimento do subalterno, afirmando que esse desenvolvimento é dificultado pelo projeto imperialista. A análise de Spivak é abordada dentro de uma coletividade intelectual denominada Grupos de estudos Subalternos, que se desenvolve nas ciências sociais aplicadas.

É da relação marcada por insurgências da ocupação colonial indiana que será extraído o primeiro argumento: o de que o sujeito que não é o subalterno normalmente atrapalha o desenvolvimento desses grupos ao representá-los por um discurso que não reflete a realidade de suas vivências. Vejamos como esse fato histórico se manifesta no exemplo da colonização indiana.

A historiografia do nacionalismo indiano foi dominada por muito tempo pelo elitismo - o elitismo colonialista e o elitismo burguês nacionalista (...) compartilh[ando] do preconceito de que a formação da nação indiana e o desenvolvimento da consciência - nacionalismo - que confirmaram esse processo foram exclusiva ou predominantemente sucessos da elite. Nas historiografias colonialistas e neocolonialistas, esses sucessos são creditados aos governantes coloniais britânicos, aos administradores, às políticas, às instituiçóes e à cultura, todos britânicos; nos escritos nacionalistas e neonacionalistas os são às personalidades, às instituiçôes, às atividades e às ideias da elite indiana. (GUHA, 2010, p. 56).

Fica evidente, nesse exemplo, como o processo de colonialismo deu origem a um outro sujeito, que náo se identificava com a narrativa colonial, mas que identificava nela, ao contrário, uma forma de restrição da narrativa de si: um 
problema frente a seu próprio desenvolvimento como sujeito que pensa sobre sua história. Esse mesmo processo se repetiu pelo mundo e, entre seus resquícios, se mantém a subalternidade.

Ao falar sobre a consciência do subalterno, Spivak tece sua crítica ao etnocentrismo da produção sobre o sujeito. Fala do papel do historiador enquanto mero "receptor", que transforma uma insurgência em um "texto para conhecimento". O "sujeito" que surge desses textos de insurgência pode, então, "servir apenas como uma contrapossibilidade para as sançóes narrativas conferidas ao sujeito colonial nos grupos dominantes". Para Spivak "no contexto de produção colonial o sujeito subalterno não tem história e não pode falar” (SPIVAK, 2010).

Dessa forma, o sujeito e o outro foram construídos pela teoria imperialista, cuja mecânica distorceu o outro em razão de sua própria incapacidade de transportar a real experiência dos sujeitos subalternos pela visão colonizadora, e também pelo fato de que os sujeitos inseridos nessa produção o fazem de forma a mimetizar a ordem de dominação posta. Ainda mais: o próprio agenciamento na teorização de outros sujeitos se caracteriza como forma de silenciamento da produção do outro sobre si, impedindo o subalterno de falar.

\section{Os grupos marginais podem constituir direitos?}

Surge, então, o questionamento: o sujeito subalterno e marginalizado pode constituir direitos em igualdade de condiçôes em relação ao sujeito de direito? O discurso do outro sujeito pode constituir algum direito? Nas palavras de Spivak: o subalterno pode falar? Instaura-se a pergunta: "O que a elite deve fazer para estar atenta à construção contínua do subalterno" (SPIVAK, 2010, p. 85).

A formação ideológica do sujeito na história é a própria fundamentação da produção do silenciamento do sujeito subalterno, que se opera por meio da representação realizada pelo teórico ocidental.

Desta forma, quando formos confrontados com as perguntas: "pode o subalterno falar?” e "pode a mulher subalterna falar?", nossos esforços para dar ao subalterno uma voz na história estarão duplamente suscetíveis aos perigos que incorre o discurso [de Freud]. Como um produto dessas consideraçóes, elaborei a sentença "homens brancos estão salvando mulheres de pele escura de homens de pele escura" (SPIVAK, 2010, p. 91).

O que Spivak pretende é, em suas palavras: "explicar a dissimulação ideológica da economia política imperialista e delinear uma história de repressão 
que produz uma sentença como a que esbocei”. A autora pretende o mesmo no exemplo em que a "viúva hindu sobe a pira funerária do marido morto e imola-se sobre ela. Esse é o sacrifício da viúva”. Um ritual hindu, abolido pelos colonizadores britânicos, um exemplo da sentença de Spivak, em que um homem branco colonizador salva mulheres "de pele escura" de homens "de pele escura" (SPIVAK, 2010, p. 93).

Spivak chama a atenção para a produção da história centrada no homem branco, no colonizador imperialista, coloca o outro sujeito numa posição do diferente, uma posição que é inferior. Isso imbui os processos dos grupos dominantes de um significado de "explicar o diferente" ou - o que é ainda mais grave - de "salvação do diferente".

Obviamente não estou advogando a matança de viúvas. Estou sugerindo que, entre as duas versôes opostas de liberdade, a constituição do sujeito feminino em vida é o lugar do différend. No caso da autoimolação das viúvas, o ritual não está sendo redefinido como uma superstição, mas como um crime. A gravidade do sati foi ele ter sido ideologicamente imbuído do sentido de "recompensa", assim como a gravidade do imperialismo foi ele ter sido ideologicamente imbuído do sentido de uma "missão social" (SPIVAK, 2010, p. 105).

É importante destacar a crítica feminista contida no pensamento de Spivak, que destaca, além das questóes coloniais e socioeconômicas, a situação de subalternidade da mulher na sociedade. Esse ponto pode ser observado quando Spivak conta sobre a jovem Bhuvaneswari Bhaduri, que se descobriu fazendo parte de um grupo armado pela libertação da Índia e que se suicidou em função de suas convicçóes pessoais a respeito de um assassinato político, o que se recusou a cometer.

Spivak narra como o discurso que se sucedeu à morte de Bhuvanewari é concebido de forma que o relato hegemônico que se constrói fosse silenciador do subalterno. Spivak afirma que o subalterno, como um sujeito feminino, náo pode ser ouvido ou lido, ao que parece sugerir que até uma forma tão drástica de manifestação do sujeito mulher será lida, interpretada e representada sempre de forma distorcida (SPIVAK, 2010). Ela conclui:

O subalterno não pode falar. Não há valor algum atribuído à "mulher" como um item respeitoso nas listas de prioridade globais. A representação não definhou. A mulher intelectual como intelectual tem uma tarefa 
circunscrita que ela não deve rejeitar como um floreio (SPIVAK, 2010, p. 126).

A conclusão de Spivak nos possibilita perceber que o subalterno não pode falar, porque as relaçóes das sociedades pós-coloniais deixaram o projeto imperialista como sua base estrutural. Assim, a produçáo intelectual sobre o sujeito adquiriu um caráter colonial, hegemônico, masculino e branco, tornando-se a representação do sujeito colonizador, que é o próprio sujeito de direito: de direitos que ele inspira e cria para si. A teoria que esse sujeito produz sobre o sujeito é sempre universalista, tolhida da realidade dos outros sujeitos.

A nova ascensão do autoritarismo que marca os governos ultraconservadores levanta essas questóes. Isso, porque os desafios sociais contemporâneos são mais uma vez moldados a partir de discursos políticos que reestabelecem relaçóes de dominação e subalternidade entre sujeitos na sociedade.

É possível destacar o exemplo da liberdade de expressão e da liberdade acadêmica para o ensino sobre gênero e diversidade sexual, que marcaram a discussão política no Brasil dos últimos anos.

Acontece que, de um lado, o grupo dominante, composto pelos sujeitos que podem falar e, portanto, constituir direitos para si, fomenta um discurso que oprime todas as formas de dissidência sexual e de gênero. De outro, o grupo dominado, composto por sujeitos em relaçáo de marginalidade fundada em bases identitárias comuns de sexo, gênero e/ou diversidade sexual adota práticas discursivas de resistência contra a insurgência dessas práticas conservadoras e excludentes.

A repressão e censura da educação sobre gênero e diversidade sexual. Trata das estratégias de poder que reprimem que os denominados "Estudos sobre gênero" surgidos no século XX na sociologia crítica norte-americana sejam levados para a educação básica brasileira. O que significa que, o ensino sobre sexualidade, precário no Brasil [...] ainda parte eminentemente de um ponto de vista binário, cisgênero e compulsoriamente masculino e heterossexual. Logo, a importância da alteração do paradigma da educação sobre sexualidade no Brasil interfere diretamente em um grupo. $\mathrm{O}$ grupo das "minorias, com bases identitárias definidas a partir do sexo/gênero e ou diversidade sexual". (CAETANO, 2019, p. 94).

Os desafios sociais relacionados à sexualidade não são pontuais ou isolados. O exemplo acima é representativo de forças e estratégias de repressão discursiva 
e política que representam e agenciam o outro sujeito, criando uma distorção da sua realidade e impedindo sua plena integração, produzindo e reproduzindo a relação de dominação, marginalidade e subalternidade.

Aquele que pertence a uma classe socialmente marginalizada e se encontra fora da posição de marginalidade intelectual ou de instrução tem uma tarefa que náo deve rejeitar em relação ao seu grupo marginalizado. Deve usar o espaço que tiver para levantar e problematizar essa questáo. Deve pensar o discurso de quem não pode falar em igualdade.

A teoria do sujeito colonial sempre interpretará e descreverá os outros sujeitos a partir de seu ponto de vista, de fora da realidade desses sujeitos, produzindo sempre uma distorção. Ao representar o outro sujeito, subalterno, essa teoria faz com que seja silenciada a sua produção de si, ao mesmo tempo em que produz as condiçóes mesmas de sua subalternidade.

O subalterno não pode falar, pois não há valor atribuído a qualquer subalterno como um item de prioridade global ou local. Muito pelo contrário, os discursos sobre o sujeito têm em sua agenda os interesses que produzem e reproduzem as estruturas de dominação.

\section{Conclusão}

O objetivo deste trabalho foi o de questionar se os grupos subalternos de uma estrutura social podem constituir direitos para si, ascendendo socialmente, de forma a se aproximar da experiência de ser um sujeito de direito.

Coube-nos destacar quem é o sujeito subalterno, e de onde deriva essa condição: da marginalidade. Como afirmamos anteriormente, sabe-se quem é o sujeito de direito: é aquele da teoria hegemônica, masculina, branca, europeia, pertencente aos altos extratos sociais, às classes dominantes, que construiu para si uma categoria formal abstrata que atende aos interesses desses grupos sociais dominantes. É o burguês, que não é nobre, mas que quer para si direitos, por ser humano, e que, por meio de um processo de consciência e tomada do poder econômico, utilizou-se do Direito para se garantir. Há ainda uma peculiaridade que é importante destacar neste trabalho: o sujeito de direito é uma categoria de reconhecimento jurídico e político, tido como naturalmente evidente. O substrato econômico não foi suficiente para garantir os direitos dos sujeitos burgueses, sendo necessário - e conquistado - o reconhecimento político-jurídico de sua condição enquanto classe sujeita a direitos.

O processo de formação do sujeito (de direto) acaba por criar um outro sujeito, que embora dotado da mesma condição, de humano, não fruía efeti- 
vamente dos direitos do sujeito de direito, nem conseguia constituir direitos para si. Identificamos, nas valiosas liçóes de Anibal Quijano, que era a condição de marginalidade que fundamentava a estratificação social. Fica evidente que a questão do marginal, que gera um sujeito subalterno na sociedade, não é uma questão dos direitos formalmente postos, mas sim uma questão das barreiras de integração de alguns grupos sociais para constituir para si esses direitos.

O indivíduo que frui efetivamente dos direitos inerentes ao sujeito de direito é quem torna a vontade livre, em razão da sua possibilidade de expressá-la. $\mathrm{O}$ indivíduo em situaçóes de marginalidade não o faz. A sociedade em que a marginalidade se produz é aquela na qual os grupos existentes, diversos e plurais, apresentam problemas de integração, estabelecendo relações de dominação econômica e/ou jurídico-política.

O sujeito subalterno, que não frui efetivamente de seus direitos humanos, enxerga a referência de seu dever ser no sujeito de direito, mas náo é plenamente incorporado a essa categoria, experimentando barreiras para sua efetiva incorporação e tornando-se, por isso, marginal.

Identificamos no trabalho de Spivak, Pode o subalterno falar?, como as relaçóes coloniais produziram a forma como se entende e se dá voz aos sujeitos pertencentes aos grupos dominados na sociedade, a quem a autora denomina "subalternos".

A crítica principal de Spivak dirige-se à produção teórica sobre os sujeitos, que, realizada por grupos dominantes, fala sobre os subalternos de fora da experiência real de suas vivências, em vez de garantir mecanismos para que esses grupos possam falar por si mesmos.

Para Spivak, essa postura colonial de produção intelectual distorce a realidade desses sujeitos, silencia os grupos subalternos e cria as condiçóes mesmas de sua subalternidade.

A conclusão de Spivak nos possibilita perceber que o subalterno não pode falar, porque as relaçóes das sociedades pós-coloniais deixaram o projeto imperialista como resquício, e a produção intelectual sobre o sujeito adquiriu um caráter colonial, hegemônico, masculino e branco: o que é a representação do sujeito colonizador, que é o próprio sujeito de direito - dos direitos que ele inspira e cria para si.

A teoria que esse sujeito produz sobre o sujeito é sempre universalista, tolhida da realidade dos outros sujeitos. A teoria do sujeito colonial sempre interpretará e descreverá os outros sujeitos a partir de seu ponto de vista de fora da realidade desses sujeitos, produzindo sempre uma distorção. Assim, ao representar 
o outro sujeito, subalterno, essa teoria faz com que seja silenciada a sua produção de si e produz as condiçóes mesmas de sua subalternidade.

Conclui-se, portanto, que é preciso pensar o discurso de quem não pode falar em igualdade. Se o subalterno não pode falar, não pode instrumentalizar-se para constituir direitos, não vai sequer ser ouvido, nem lido, pois sua própria localização na estrutura de poder que se produz e se reproduz é a de dominado, de marginal. Logo, a resposta ao objeto precípuo deste trabalho - grupos marginais podem constituir direitos? - tem de ser não. Ou, melhor: sim, mas, em primeiro lugar, eles precisam poder falar.

\section{REFERÊNCIAS}

ALTHUSSER, L. Ideologia e aparelhos ideológicos do Estado. São Paulo: Martins Fontes; Lisboa: Presença, 1976.

CAETANO, F. Liberdade de expressáo e liberdade acadêmica para a educaçáo sobre gênero e diversidade sexual. 2019. 169 f. Dissertação (Mestrado em Direito) Faculdade de Direito, Universidade Federal de Minas Gerais, Belo Horizonte, 2019.

GUHA, R. Subaltern Studies I: Writing on South Asian History and Society. In: SPIVAK, G. Pode o subalterno falar?. Trad. Regina Goulart Almeida et al. Belo Horizonte: Ed. da UFMG, 2010. p. 7-127.

KASHIURA JR., C. N. Sujeito de Direito e Capitalismo. 2012. 177 f. Tese (Doutorado em Filosofia e Teoria Geral do Direito) - Faculdade de Direito, Universidade de São Paulo, São Paulo, 2012.

LIBERA, A. de. Arqueologia do Sujeito: Nascimento do Sujeito. Trad. Fátima Conceição Murad. São Paulo: FAP-UNIFESP, 2013.

LUKÁCS, G. História e consciência de classe: estudos de dialética marxista. São Paulo: Martins Fontes, 2003.

MACDONALD, E. The trouble with subjects: Feminism, Marxism and the questions of Poststructuralism. Studies in Political Economy, Abingdon, v.35, p. 43-71, 1991.

MARX, K. Manuscritos econômico-filosóficos. Tradução de Jesus Raniere. São Paulo: Boitempo, 2004 [1844].

MÉSZÁROS, I. A Teoria da Alienaçáo em Marx. Trad. Isa Tavares. São Paulo: Boitempo, 2006. 
QUIJANO, A. Notas sobre o Conceito de Marginalidade Social. In: PEREIRA, L. (org.). Populaçóes Marginais. São Paulo: Duas Cidades, 1978. p. 13-71.

SPIVAK, G. Pode o subalterno falar?. Trad. Regina Goulart Almeida et al. Belo Horizonte: Ed. da UFMG, 2010.

TOURAINE, A. The Subject is Coming Back. International Journal of Politics, Culture, and Society, New York, n. 18, p. 199-209, 2005.

TOURAINE, A. Crítica da Modernidade. Trad. Elia Ferreira Edel. Petrópolis, RJ: Vozes: 1994a.

TOURAINE, A. Crítica de la Modernidad. Trad. Alberto Luis Bixio. Buenos Aires: Fonto de Cultura Economica de Argentina, 1994 b.

Recebido em 23 de março de 2020.

Aprovado em 04 de junho de 2020. 